\title{
ВмJ Global Health Mortality surveillance and verbal autopsy strategies: experiences, challenges and lessons learnt in Papua New Guinea
}

\author{
John D Hart (D , ${ }^{1}$ Viola Kwa, ${ }^{1}$ Paison Dakulala, ${ }^{2}$ Paulus Ripa, ${ }^{3}$ Dale Frank, ${ }^{4}$ \\ Theresa Lei, ${ }^{5}$ Ninkama Moiya, ${ }^{6}$ William Lagani, ${ }^{7}$ Tim Adair (1) , ${ }^{1}$ \\ Deirdre McLaughlin, ${ }^{1}$ Ian D Riley, ${ }^{1}$ Alan D Lopez ${ }^{1}$
}

To cite: Hart JD, Kwa V, Dakulala P, et al. Mortality surveillance and verbal autopsy strategies: experiences, challenges and lessons learnt in Papua New Guinea. BMJ Global Health 2020;5:e003747. doi:10.1136/ bmjgh-2020-003747

Handling editor Soumitra S Bhuyan

- Additional material is published online only. To view, please visit the journal online (http://dx.doi.org/10.1136/ bmjgh-2020-003747)

JDH and VK contributed equally.

Received 18 August 2020 Revised 25 October 2020 Accepted 10 November 2020

Check for updates

(C) Author(s) (or their employer(s)) 2020. Re-use permitted under CC BY-NC. No commercial re-use. See rights and permissions. Published by BMJ.

For numbered affiliations see end of article.

Correspondence to

Dr John D Hart:

john.hart@doctors.org.uk

\section{ABSTRACT}

Full notification of deaths and compilation of good quality cause of death data are core, sequential and essential components of a functional civil registration and vital statistics (CRVS) system. In collaboration with the Government of Papua New Guinea (PNG), trial mortality surveillance activities were established at sites in Alotau District in Milne Bay Province, Tambul-Nebilyer District in Western Highlands Province and Talasea District in West New Britain Province.

Provincial Health Authorities trialled strategies to improve completeness of death notification and implement an automated verbal autopsy methodology, including use of different notification agents and paper or mobile phone methods. Completeness of death notification improved from virtually $0 \%$ to $20 \%$ in Talasea, $25 \%$ and $75 \%$ using mobile phone and paper notification strategies, respectively, in Alotau, and 69\% in Tambul-Nebilyer

We discuss the challenges and lessons learnt with implementing these activities in PNG, including logistical considerations and incentives.

Our experience indicates that strategies to maximise completeness of notification should be tailored to the local context, which in PNG includes significant geographical, cultural and political diversity. We report that health workers have great potential to improve the CRVS programme in PNG through managing the collection of notification and verbal autopsy data. In light of our findings, and in consultation with the main government CRVS stakeholders and the National CRVS Committee, we make recommendations regarding the requirements at each leve of the health system to optimise mortality surveillance in order to generate the essential health intelligence required for policy and planning.

\section{INTRODUCTION}

The civil registration and vital statistics (CRVS) system in Papua New Guinea (PNG) is largely ineffective and there are multiple challenges to creating a system with complete birth and death registration. Prior to independence in 1975, the country's CRVS system
Summary box

Mortality surveillance as part of government programmes has been successfully introduced in three provinces in Papua New Guinea: (Milne Bay, West New Britain and Western Highlands).

- Successful notification and verbal autopsy (VA) strategies require planning at the local level and selection of appropriate notification agents and VA interviewers, in particular that they have positions of trust in the community.

- It is essential that notification and VA data collection activities are integrated into official staff duties, from national and provincial administrators to health workers and ward-level notifying agents.

- Following civil registration and vital statistics (CRVS stakeholder discussions in PNG, we identify the key steps required to establish a functional mortality surveillance system in PNG, and present this blueprint as online supplemental material.

- Health workers should be the agents responsible for electronic entry of notification and cause of death data into PNG's eNHIS (electronic National Health Information System) platform, as identified by government stakeholders in CRVS business process maps, and endorsed by the national CRVS Committee (business process maps are included as online supplemental material).

- Facilitating health workers to manage notifications and conduct VAs, with data shared between the National Department of Health and PNG Civil and Identity Registry, could greatly improve the country's CRVS programme.

functioned mostly for expatriates living in colonial administrative centres and restricted government stations. PNG's Civil Registration Act of 1963 was based largely on Australia's Queensland state law and does not provide a sound basis for a functional modern CRVS system for the country. As the value of reliable, timely and relevant mortality data 
becomes increasingly apparent, a new Civil Registration Bill (CR Bill) has been drafted and is due to be read in parliament in 2021, that will facilitate the use of modern data systems and streamlined notification strategies. In addition, PNG has opened civil registry offices in many provinces and has mobile teams as part of a current drive to rollout National Identification (NID) cards to all citizens. While NID rollout is a government priority, there is growing high level recognition of the importance of birth and death notification and registration to produce useful vital statistics data, particularly given the importance of death notification for the deletion of NID cards to minimise their fraudulent use.

We have been working with the government of PNG to develop the CRVS system, in particular with the National Department of Health (NDOH) to support mortality surveillance. Prior to the intervention, the vast majority of mortality data for PNG were derived from health facility discharge summaries, producing biassed estimates largely not accounting for approximately $75 \%$ of deaths that occur in the community and are almost entirely unregistered. ${ }^{1}$ In addition, the discharge summaries do not record cause of death in the internationally recognised manner on a Medical Certificate of Cause of Death (MCCOD) and therefore coding of an underlying cause of death is not possible, resulting in lower quality records of limited value for policymakers. We have supported physician training to improve the quality of MCCODs and also the introduction of verbal autopsy (VA), a technique for inferring most likely cause of death for unattended deaths from an interview with a relative of the deceased. ${ }^{2}$

PNG is in the process of expanding an electronic National Health Information System (eNHIS) that is intended to collect individual level data from health centres and hospitals, ideally forming the basis of a modern and comprehensive mortality surveillance system. A major challenge in the development of such a system is gathering data on the 'fact' of deaths occurring in the community, to then use VA methodology to reliably and quickly diagnose causes of death. Very little empirical research is available to guide the development and evaluation of approaches to improving death notification and diagnosis in PNG. In response, we have been piloting strategies to facilitate reporting of deaths at the ward level, and subsequent VA diagnoses by health staff, to generate data about the leading causes of community deaths, hitherto unavailable for PNG.

Our experience demonstrating strategies for death notification and subsequent VA diagnoses by health staff have resulted in useful, policy relevant information for PNG. The findings have been strikingly different from the the Global Burden of Disease Study (GBD), indicating a higher proportion of deaths due to infectious diseases $(27.0 \%)$, a lower proportion of non-communicable disease deaths (50.8\%) and a higher proportion of injury deaths $(22.5 \%)$ than the GBD estimates, reflecting longstanding expert opinion in the country that progression of the epidemiological transition has been overestimated by GBD (unpublished data). In addition, the VA results emphasise the epidemiologically diverse nature of mortality trends across the surveillance sites.

The optimal operational characteristics of data collection systems, such as death notification and VA, particularly in a society as diverse as $\mathrm{PNG}$, require careful selection and evaluation, building on local community structures as much as possible. In this paper, we describe a series of interventions that were implemented to generate policy-relevant data to guide health development in the country, our successes as well as challenges and attempted solutions. Based on the lessons learnt, we draw conclusions about how best to address some of the multiple challenges facing the further development of CRVS systems in PNG.

\section{DEATH NOTIFICATION}

We implemented strategies to improve death notification in PNG in three districts starting in 2018. Districts were selected from three of PNG's four regions: the Highlands Region, Islands Region and Southern Region, each with their own rich diverse cultural and political circumstances. Intervention sites were not selected to be representative of the country but rather to identify challenges associated with working in different regions in order to inform future planning and implementation of government programmes. The three districts were: Alotau in Milne Bay Province; Talasea in West New Britain Province; and Tambul-Nebilyer in Western Highlands Province. The underlying strategy in all intervention sites was for community-level notifying agents to inform the nearest health centre of any deaths in their designated area and for these to then be followed up by health workers to verify the data, complete an electronic notification form and conduct a VA.

In two intervention districts, Alotau and Talasea, Ward Recorders (WRs) were selected as notification agents. The WR system was first introduced across PNG under the Department of Provincial and Local Government Affairs (DPLGA) in 1997 and WRs kept a ward record book of key indicators from their ward communities. There was no system for compiling data from the wards and data collection ceased in most of the country. In a minority of districts, updated ward record books have been reintroduced, including Alotau and Talasea. At these sites, we provided training jointly with DPLGA for the WRs on both completion of the ward record book and vital event notification. Training was face-to-face, conducted in each Local Level Government (LLG) and of 1 day duration.

In Alotau District, strategies were implemented to compare paper notification methods with mobile phone shortmessaging service (SMS) notification. In three LLG areas, WRs were provided with basic mobile phones and credit to notify deaths to the health system. An SMS containing basic data on the deceased and their location was sent to a tablet located at the nearest health centre 
to trigger completion of the electronic notification and VA interview. In the other three rural LLGs, the WRs were trained to complete paper notification forms and deliver them to the nearest health centre. In Talasea District, where WRs were also engaged as notification agents, it was decided with West New Britain Provincial Health Authority (PHA) that paper notification forms would be most appropriate due to the district's relatively better transport connections that would facilitate transfer of paper forms, and relatively poor telecommunication networks.

In Tambul-Nebilyer District, the WR system was not functional and Village Health Volunteers (VHVs) were proposed by Western Highlands PHA as the most appropriate notification agents. VHVs are generally older, local women with low levels of literacy (overall literacy rate $44 \%$ for adults over 50 years of age in PNG, with the Highlands Region also having the greatest disparity between men and women). ${ }^{3}$ Their typical day involves tending crops and animals, collecting firewood and water and other household chores, in addition to their unpaid health support activities. VHVs received the same 1 day notification training as WRs. Due to similar transport and telecommunications connectivity as in Talasea, as well as difficulties related to the use of mobile phones in Alotau, paper notification forms were used in Tambul-Nebilyer.

We estimated notification completeness using crude death rates (CDRs) and district populations derived from the 2011 census and projected to the midpoint of data collection using the population growth rate between the 2000 and 2011 censuses. ${ }^{4}$ Estimates of CDRs were 7.2/1000 in Milne Bay; 5.3/1000 in Western Highlands; and 6.2/1000 in West New Britain. ${ }^{1}$ Completeness was calculated for deaths occurring between January 2018 and September 2019 as the project was set up to conduct VAs retrospectively for any deaths during this period. Data collection commenced in June 2018 in Alotau District, followed by Talasea District and Tambul-Nebilyer
District in September 2018. Notification completeness increased from a baseline of zero or minimal deaths being notified, to between $13 \%$ and $47 \%$ over the first 9 months of the project, as reported by Adair et al (2020). ${ }^{5}$ By September 2019 estimated completeness was $20 \%$ in Talasea; $25 \%$ and $75 \%$ using mobile phone and paper notification strategies, respectively, in Alotau; and $69 \%$ in Tambul-Nebilyer (table 1). Completeness was calculated for community deaths as a proportion of total estimated deaths in each district; an additional $10 \%$ to $15 \%$ of total deaths are expected to have occurred in health facilities.

All intervention sites included some remote populations that are difficult to access and therefore a particular challenge to achieving high levels of notification and VA. Tambul-Nebilyer had the highest districtwide estimate of notification completeness, despite also having remote areas as well as the low literacy levels of VHVs. In this district, the combination of VHVs' knowledge of their communities, and ward visits by VA interviewers, facilitated notification of the majority of deaths. In contrast, the lowest estimate of notification completeness was $20 \%$ in Talasea. This district has extensive remote areas and significant unrest during the intervention meant health services were restricted in some localities. In Alotau, completeness increased during the study period as it became evident that training community health workers (CHWs) from remote aid posts on VA improved notification due to their excellent understanding of, and contacts in, their catchment wards.

\section{VERBAL AUTOPSY}

Health workers, including health extension officers, nurses and community health workers were trained at each site to follow-up notification of deaths with household visits to verify the notification data, complete an electronic notification form and conduct the VA interview, using the SmartVA tool. ${ }^{6}$ Training was of 3 days' duration

Table 1 Death notification completeness in mortality surveillance sites in Papua New Guinea, 2018 to 2019

\begin{tabular}{|c|c|c|c|c|}
\hline Intervention site & $\begin{array}{l}\text { Alotau (Huhu, } \\
\text { Suau and Weraura } \\
\text { LLGs) }\end{array}$ & $\begin{array}{l}\text { Alotau (Daga, } \\
\text { Makamaka and } \\
\text { Maramatana } \\
\text { LLGs) }\end{array}$ & Talasea & Tambul-Nebilyer \\
\hline Notification agents & Ward recorders & Ward recorders & Ward recorders & $\begin{array}{l}\text { Village health } \\
\text { volunteers }\end{array}$ \\
\hline Method & Mobile phone SMS & Paper & Paper & Paper \\
\hline Number of wards & 88 & 63 & 68 & 86 \\
\hline $\begin{array}{l}\text { Estimated population at the midpoint of data } \\
\text { collection }\end{array}$ & 74021 & 32323 & 246585 & 87273 \\
\hline $\begin{array}{l}\text { Expected deaths during the data collection } \\
\text { period }\end{array}$ & 935 & 408 & 2658 & 814 \\
\hline Notifications received & 231 & 306 & 537 & 558 \\
\hline Estimated completeness & $25 \%$ & $75 \%$ & $20 \%$ & $69 \%$ \\
\hline
\end{tabular}

LLG, Local Level Government; SMS, short messaging service. 
and included multiple aspects regarding the VA interview, including confidentiality and ethics. Data collection used Open Data Kit (ODK) software on Android devices and data were uploaded to a server accessed at NDOH. A VA field coordinator was recruited in each implementation district, to work with the PHA and facilitate the local death notification strategy, including linking of notification agents with VA interviewers at the health centre and supervising some VA interviews. The field coordinator roles were important for the intervention to gain traction prior to VA becoming an accepted routine activity of health workers. The field coordinators reported to VA coordinators (doctors based at the provincial hospitals), who directed feedback to the interviewers, as required.

Tablets containing VA software were based at health centres initially, then further rolled out to targeted smaller aid posts, some located 1 to 2 days' travel time from health centres. Rollout to aid posts, thereby reducing interviewer travel time, demonstrably improved death notification coverage. In addition, the previously established rapport of CHWs in their aid post catchment areas, facilitated VA data collection, including for deaths that occurred in difficult circumstances, such as suicides. CHWs were generally excited to be included, attend training and be able to perform a new skill. CHWs usually visit the health centre once a month for supplies and reporting. At these visits, CHWs who had not been supplied with a tablet could be provided with the health centre device to conduct VAs in the vicinity of their aid post as well as further a field during outreach visits for child health and antenatal clinics.

\section{INCENTIVES}

Following training courses for WRs on death notification, and for health workers on the electronic notification form and VA, initial data collection proceeded relatively slowly.

A government National Executive Council decision in 2014 increased WR monthly allowances to K200 (US\$58.80)/month but payment was not occurring. The provincial government in Alotau had determined to pay WRs their allowance, as opposed to leaving this as the responsibility of DPLGA. However, payments were usually severely delayed, and the WRs in both Alotau and Talasea regularly informed us that they were reluctant to notify deaths without their allowances being paid or other incentives provided. It was also apparent that health workers, particularly in the early stages of implementation, did not view VA activities as a core part of their work, either in their job descriptions or reporting requirements.

While advocating for increased high level involvement and recognition of the essential role of government to progress mortality surveillance activities, an incentive system was introduced to compensate WRs for their time to provide death notifications and for health workers' time to complete VA interviews (K5 (US\$1.47) per notified death for WRs and K10 (US\$2.94) per VA conducted by health staff). This was widely publicised to be a temporary measure while VA and notification were integrated into provincial systems, to minimise the risk of non-sustainable long-term expectations of increased funding. The cumulative distribution of VAs conducted during the study is shown in figure 1 . The effect of the incentive system, introduced in February 2019, can be seen as an increased rate of data collection at all sites, particularly helping start the programme in TambulNebilyer and Talasea. Higher rates of VA collection were evident for the rest of the follow-up period, during which the incentive system remained in place.

Separate from monetary incentives to improve motivation, we also provided health workers with regular feedback of VA results and facilitated group discussions between staff from different provinces. This engagement of staff, acknowledgement of challenges and demonstration of the utility of their work for policy, appeared to increase productivity, although we do not have evidence to show this.

\section{LOGISTICAL CONSIDERATIONS}

The mobile phone notification strategy in Alotau removed the requirement to print and distribute paper forms, but some WRs encountered significant challenges, including poor telecommunication network, inexperience with mobile phone technology, broken devices and regular draining of credit. In addition, poor electricity coverage in rural areas of PNG posed problems for the use of electronic devices. From the perspective of the health system receiving notifications, the health workers generally preferred WRs to complete the paper forms, which contained all the required details for them to complete the electronic notification on the tablet.

In Tambul-Nebilyer District, the VHVs' main activities were as the first point of contact for health advice in their community, with a particular focus on advising expectant mothers regarding antenatal services. They had almost unparalleled knowledge of their communities, but their lack of formal education and volunteer status required adaptation of the approach compared with the WR strategy. More so than in the other districts, the VA field coordinator was required to visit each VHV to gather notification data for delivery to VA interviewer staff at the health centres.

In Talasea District, plans were made to incorporate VA activities under the Clinical Outreach Program. While this appeared promising during the early stages of implementation, it became clear that the arrangement would not be able to facilitate VA activities in the absence of additional funding for Clinical Outreach. Without this support, VA funding, for example, for travel to communities, could only support a limited number of Community Outreach visits. This was the main challenge limiting death notification completeness at this site. 

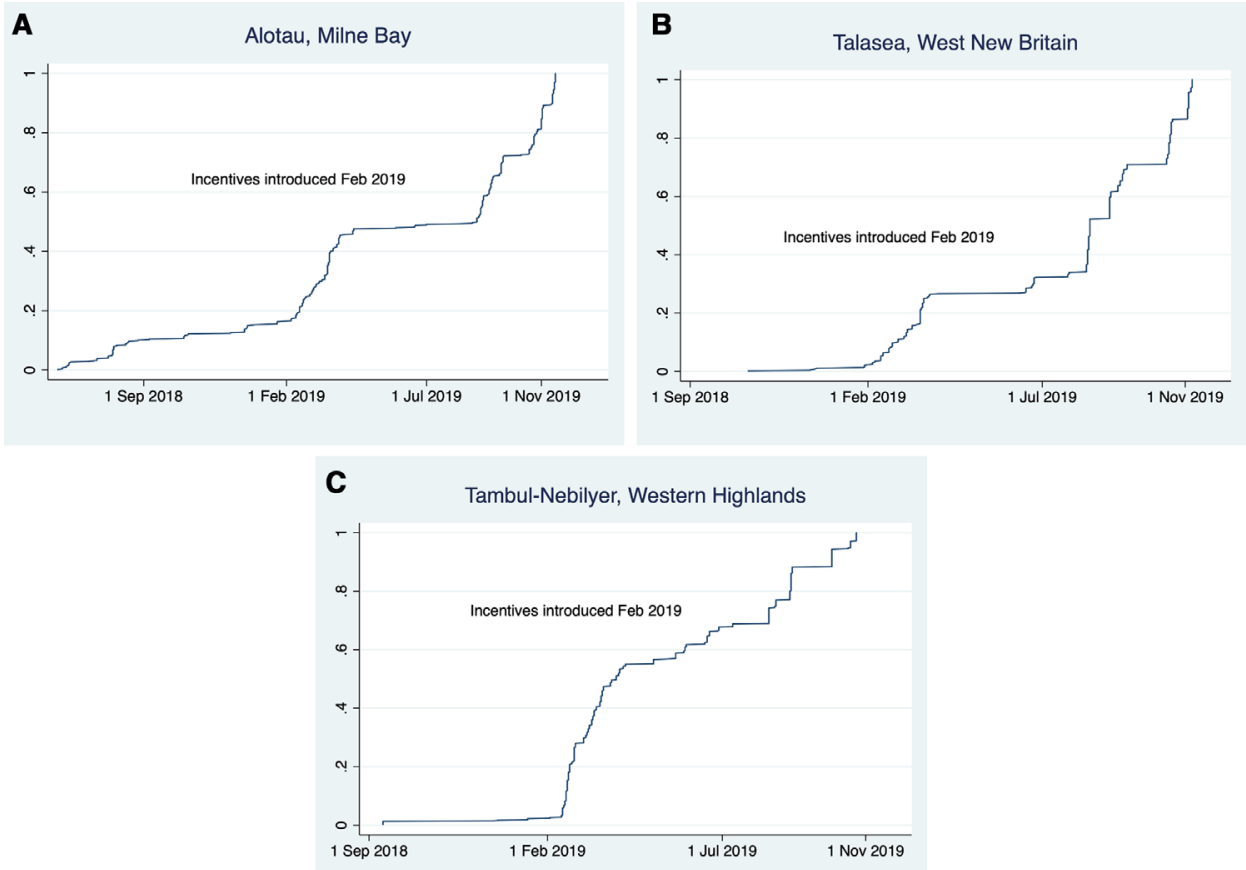

Figure 1 Cumulative distribution of verbal autopsies conducted in each mortality surveillance district during the study: (A) Alotau District, Milne Bay Province. (B) Talasea District, West New Britain Province. (C) Tambul-Nebilyer District, Western Highlands Province.

\section{DEVELOPING A NATIONAL MORTALITY SURVEILLANCE SYSTEM}

PNG, with mountainous highland areas as well as multiple islands, has always posed unique challenges for governments trying to expand services. Corruption, tribal conflicts and ethnolinguistic favouritism all affect stability and service provision. Business Process Mapping exercises, involving all CRVS stakeholders, showed the main impediment to birth and death registration was the initial notification of events in rural communities. ${ }^{7}$ The health system was identified as the best option for implementing and maintaining a repository for both notification and cause of death data from VA and MCCOD. The 'as-desired' process maps were endorsed by the national CRVS Committee and are available as online supplemental figure 1.

There is broad agreement that health workers should be the agents responsible for electronic entry of notification and cause of death data into the eNHIS platform. Data would have to be available to senior health staff in real time, with a dedicated team for analysis and interpretation, as well as subsequent policy recommendations. Provincial health administrators would require access to data to ensure data quality, and health facility staff would require access to notification, VA and MCCOD data for their own facility, with the system prompting completion of VA or MCCOD, as appropriate, for each notified death. In addition to a national committee, provincial committees would be expected to review the data locally to maximise utility for health policy. Importantly, verified mortality data would have to be made available to PNG Civil and Identity Registry (PNGCIR) from eNHIS for the purposes of official death registration and certification.
Certificates could then be produced at, or delivered to, the local health facility for distribution to families.

There are historical and political barriers that limit data sharing between government departments in PNG although there is increasing recognition that these must be overcome to drive progress. A recently endorsed National Action Plan for CRVS in PNG emphasises that collaboration, particularly between PNGCIR and $\mathrm{NDOH}$, will be key to further improving systems. ${ }^{8}$ While the improvements in notification produced by the interventions described here were not as great as might be expected, the procedures, skills and knowledge that have been established in these districts should enable government agencies working together to significantly increase notification completeness in the coming years.

There is general agreement that the ideal system in PNG would enable multiple potential notification agents (identified at the ward level in online supplemental figure 2), which is being captured in the Regulations to the new CR Bill. The requirements for a functional mortality surveillance system at each level of the health system are included as online supplemental figure 3). While this blueprint is specific for PNG, the requirements are expected to be broadly similar in other countries facing similar challenges in the notification of vital events. This includes, in particular, a thorough understanding of the administrative and social structure at the provincial, district and community level. Local support and incorporation of activities into current roles and systems is essential for good coverage and sustainability of these interventions in the low resource settings where they are required. 


\section{CONCLUSION}

Our experience in trialling and refining strategies to improve death notification and cause of death reporting in PNG suggests that while it is possible to collect and maintain systems of data collection, there are several challenges to resolve. Strategies to maximise completeness of notification should take into account the local context, which in PNG includes considerable geographical, cultural and political diversity. It is essential that data collection activities are integrated into official staff duties, from national and provincial administrators to health workers and ward-level notifying agents. The nascent eNHIS system in PNG provides an ideal opportunity to capitalise on the potential benefits of electronic data capture, transfer and management to improve completeness and timeliness of notification and VA data.

We have demonstrated that death notification from the ward level, through training WRs and VHVs, can be integrated into a routine system for reporting vital events and diagnosing causes of death. In addition, we have shown that empowering health workers to manage these notifications and conduct VAs can be successfully implemented at a district level, suggesting that facilitating health workers to conduct these activities, with data shared between $\mathrm{NDOH}$ and CIR, could greatly improve the country's CRVS programme. Our experience from PNG suggests that flexible, low cost strategies to identify the fact of death and diagnose the cause can indeed be expected to strengthen national mortality surveillance and generate the essential health intelligence that is fundamental for informed health policy, and broader social development.

\section{Author affiliations}

${ }^{1}$ Melbourne School of Population and Global Health, The University of Melbourne, Melbourne, Victoria, Australia

${ }^{2}$ National Department of Health, Port Moresby, Papua New Guinea

${ }^{3}$ Western Highlands Provincial Health Authority, Mount Hagen, Papua New Guinea

${ }^{4}$ Milne Bay Provincial Health Authority, Alotau, Papua New Guinea

${ }^{5}$ West New Britain Provincial Health Authority, Kimbe, Papua New Guinea

${ }^{6}$ Papua New Guinea Civil and Identity Registry, Port Moresby, Papua New Guinea

${ }^{7}$ Central Provincial Health Authority, Port Moresby, Papua New Guinea

Acknowledgements We would like to acknowledge the Government of Papua New Guinea (PNG), in particular the National Department of Health, PNG Civil and Identity Registry, The Constitutional and Law Reform Commission, National Statistical Office, Department of Provincial and Local level Government, the Provincial Governments and Provincial Health Authorities, in Milne Bay, West New Britain and Western Highlands, who have supported the verbal autopsy intervention. In addition, we would like to thank the health workers and management staff who have coordinated and conducted the verbal autopsy interviews, in particular Martha Wame, Vincent Lagea, David Kombra, Adam Sause and Michaeline Romulars. We would also like to thank the Ward Recorders and Village Health Volunteers who enabled the notification of deaths and the government staff who assisted with the coordination of notification training and activity, in particular Nicholas Piauka and Rowen Nimb.

Funding This study was funded by Bloomberg Philanthropies.

Competing interests None declared.

Patient consent for publication Not required.

Provenance and peer review Not commissioned; externally peer reviewed.

Data availability statement All data relevant to the study are included in the article.

Supplemental material This content has been supplied by the author(s). It has not been vetted by BMJ Publishing Group Limited (BMJ) and may not have been peer-reviewed. Any opinions or recommendations discussed are solely those of the author(s) and are not endorsed by BMJ. BMJ disclaims all liability and responsibility arising from any reliance placed on the content. Where the content includes any translated material, BMJ does not warrant the accuracy and reliability of the translations (including but not limited to local regulations, clinical guidelines, terminology, drug names and drug dosages), and is not responsible for any error and/or omissions arising from translation and adaptation or otherwise.

Open access This is an open access article distributed in accordance with the Creative Commons Attribution Non Commercial (CC BY-NC 4.0) license, which permits others to distribute, remix, adapt, build upon this work non-commercially, and license their derivative works on different terms, provided the original work is properly cited, appropriate credit is given, any changes made indicated, and the use is non-commercial. See: http://creativecommons.org/licenses/by-nc/4.0/.

\section{ORCID iDs}

John D Hart http://orcid.org/0000-0002-9637-7974

Tim Adair http://orcid.org/0000-0002-1562-4452

\section{REFERENCES}

1 Kitur U, Adair T, Lopez AD. Patterns of all-cause mortality in Papua New Guinea, 2011. Asia Pac J Public Health 2019;31:315-24.

2 de Savigny D, Riley I, Chandramohan D, et al. Integrating communitybased verbal autopsy into civil registration and vital statistics (CRVS): system-level considerations. Glob Health Action 2017;10:1272882.

3 Asian Development Bank. Papua New Guinea country gender assessment, 2012

4 Papua New Guinea National Statistics Office. National population and housing census of Papua New Guinea, 2011.

5 Adair T, Rajasekhar M, Bo KS, et al. Where there is no hospital: improving the notification of community deaths. BMC Med 2020;18:65.

6 Serina P, Riley I, Stewart A, et al. Improving performance of the tariff method for assigning causes of death to verbal autopsies. BMC Med 2015;13:291.

7 Cobos Muñoz D, de Savigny D, Sorchik R, et al. Better data for better outcomes: the importance of process mapping and management in CRVS systems. BMC Med 2020;18:67.

8 Papua New Guinea Civil and Identity Registry. Papua New Guinea's national civil registration and vital statistics plan, 2019. 